\title{
A Population-Level Examination of Incarcerated Women and Mothers Before and After the California Public Safety Realignment Act
}

\author{
John Prindle ${ }^{1}$ (1) Andrea Lane Eastman ${ }^{1} \cdot$ Qianwei Zhao ${ }^{2} \cdot$ Mia Bird $^{3} \cdot$ Emily Putnam-Hornstein $^{1,4}$
}

Accepted: 22 November 2021 / Published online: 3 January 2022

(c) The Author(s), under exclusive licence to Springer Science+Business Media, LLC, part of Springer Nature 2021

\begin{abstract}
Background In 2011, California enacted its public safety realignment initiative (realignment) motivated by a U.S. Supreme Court ruling to reduce state prison overcrowding and in effort to reduce recidivism. Realignment transferred authority for lower-level felony offenders from the state to the counties, leading to a rapid reduction in state prison incarceration levels. Objective This study drew on a unique dataset to assess the effects of California's efforts to downsize the prison system on maternal incarceration levels and to better understand the characteristics of incarcerated mothers and their children.

Methods Incarceration records concerning all women in California state prisons between 2010 and $2012(N=16,917)$ were linked to 7.5 million vital birth records dating to 1999 to identify incarcerated women who had given birth. Multinomial logistic regression models were specified to better understand offense type differences among incarcerated mothers versus nonmothers.

Results Findings indicate that realignment disproportionately affected women. The number of men entering prison decreased $67.8 \%$ between 2010 and 2012. In comparison, the number of women entering prison decreased $78.5 \%$. Further, more than half of incarcerated women had given birth. Mothers were more likely than nonmothers to be convicted of nonviolent crimes. Discussion This study underscores how prison downsizing can disproportionately reduce incarceration levels for women. Given that such large proportion of incarcerated women were mothers, this policy change may have potential spillover nextgeneration benefits. Finally, this work reinforces the potential to use linked administrative records to study incarcerated populations.
\end{abstract}

Keywords Maternal incarceration · Criminal justice $\cdot$ Decarceration

\section{Significance}

What is known? Women are a growing proportion of jail and prison populations and uniquely affected by criminal justice polices given different needs.

John Prindle

jprindle@usc.edu

1 USC Suzanne Dworak-Peck School of Social Work, University of Southern California, Los Angeles, USA

2 Diana R. Garland School of Social Work, Baylor University, Waco, USA

3 Goldman School of Public Policy, University of California, Berkeley, USA

4 School of Social Work, University of North Carolina Chapel Hill, Chapel Hill, USA
What this study adds? The current analysis linked California incarceration and birth records to determine the number and characteristics of women entering prison over time and the proportion of mothers during a critical period of policy change. This study underscores how prison downsizing can disproportionately reduce incarceration levels for women. Given that such large proportion of incarcerated women were mothers, this policy change may have potential spillover next-generation benefits. This work also highlights the potential to use linked administrative records to study incarcerated populations.

\section{Introduction}

The number of incarcerated women is increasing globally, and the United States has the largest incarcerated population in the world (Walmsley, 2017). Between 1982 and 2017, the 
incarceration rate for women in the United States increased at twice the rate of men (Carson, 2020b; Zhen \& Milton, 2021). By 2019, more than 200,000 women were incarcerated nationally (an estimated 54 per 100,000 women) (Carson, 2020b).

Although women are a growing proportion of the county jail and state prison populations, they represent less than a tenth of incarcerated individuals (Walmsley, 2017). Knowledge about incarcerated women as a subgroup of the population of individuals who are incarcerated is important given different needs and unique vulnerabilities (Bloom et al., 2003). Women who are imprisoned have disproportionately higher rates of childhood victimization and adulthood mental health and substance use problems than the general population of women (Tripodi \& Pettus-Davis, 2013). Health care within county jails and state prisons in the United States typically does not meet the medical or psychological needs of female inmates (Mignon, 2016) and there is the potential for mental heath conditions to worsen during incarceration (Harner \& Riley, 2013).

Women are uniquely affected by criminal justice polices and, relatedly, women are incarcerated for different offense types than men. Among women who were incarcerated, a quarter were incarcerated for drug offenses compared to $14 \%$ of men who were incarcerated, and more than half of men were incarcerated for a violent offense compared to a third of women. Increases in the number of incarcerated women have not been attributed to changes in women's behaviors; the rate of violent crimes committed by women has remained constant over time (Carson, 2020a; Sabol et al., n.d.; Zhao et al., 2021). Increases in incarceration rates for women have been attributed to policies that disproportionately affect women, including enhanced sentencing for drug-related crimes and mandatory minimum sentencing (Kruttschnitt, 2010).

Despite efforts to decrease the prison population, California has the second highest number of individuals incarcerated in state and federal facilities and the third highest number of incarcerated women of any state (Bronson \& Carson, 2019; Carson, 2020b). In 2011, California's prison system housed nearly twice as many incarcerated individuals as its designed capacity, which the U.S. Supreme Court ruled as violating the Eighth Amendment, intended to protect citizens from excessive punishment (Brown v. Plata, 563 US 493, 2011). In 2011, the state adopted Assembly Bill 109, or the California Public Safety Realignment Act (hereafter, realignment) and implemented it in October 2011. Realignment transferred the responsibility for managing lower-level felony offenders from the state prison and parole system to county jail and probation systems, resulting in state prison incarceration rates falling by about 27,000 incarcerated individuals in the year following implementation. The county jail population increased in that same year by less than 9000 , reflecting an overall decline in incarceration levels in the state (Grattet et al., 2016; Lofstrom \& Raphael, 2015). Realignment not only induced a shift from state to county correctional systems, but also changed the incentives county criminal justice systems face when determining whether to incarcerate someone and for how long. Under realignment, counties now bear the costs of decisions to incarcerate individuals convicted of lower-level felony offenses. This change in incentives induced by realignment led to an overall reduction in incarceration in California (Bird et al., 2017, forthcoming).

Importantly, changes in incarceration policies that affect women almost certainly influence child outcomes. Estimates suggest that more incarcerated women than men report being a parent (62\% vs. 51\%) (Glaze \& Maruschak, 2008). Although more than three quarters of incarcerated mothers report living with their children the month before arrest or incarceration, this is true of less than half of incarcerated fathers. Incarcerated mothers were also 3 times as likely to be the primary caregivers of their children than fathers (77\% vs. $26 \%$ ). Further, mothers who experience both incarceration in state prison and who have a child placed in foster care are at heightened risk of losing custody of their children and termination of parental rights (Gifford et al., 2021).

Statistics concerning the number of incarcerated mothers can be challenging to establish (Bronson \& Sufrin, 2019) but are critically important. Research has shown that parental incarceration has next-generation consequences. Specifically, having a parent who is incarcerated is associated with increased risk of child learning disabilities and developmental delays, infant and child mortality, child mental health issues, and next-generation criminal justice involvement (Wildeman et al., 2018). Importantly, maternal incarceration is more strongly associated with a child's incarceration than paternal incarceration (Lee et al., 2016). Unfortunately, county jails and state prisons do not generally collect information on the parental status of incarcerated individuals in a systematically reliable form. Previous attempts at understanding the number and characteristics of incarcerated mothers or parents have relied largely on self-report surveys (Geller et al., 2016; Glaze \& Maruschak, 2008) and relatively small samples (Foster, 2012). Administrative registry data provide full, population-based censuses of individual systems and can help avoid self-report biases, which is useful when studying incarcerated women and mothers (Wildeman et al., 2018).

\section{Method}

This analysis leveraged a unique dataset, linking California incarceration and birth records to determine the number and characteristics of women entering prison over time and the proportion of mothers. Population changes, demographic 
trends, and types of offenses were assessed. The relationship between offense type and maternal status was modeled using multinomial logistic regressions. Our objective was to leverage existing data to examine incarceration experiences for women and mothers during a critical period of policy change.

\section{Data}

Data included administrative criminal justice records from the California Department of Corrections and Rehabilitation and vital birth records from the California Department of Public Health. Records concerning women incarcerated in California state prisons before and after realignment (2010-2012) and who were 44 years old or younger at the start of the episode were extracted $(N=16,102)$. The population was restricted by age to align with the availability of birth records dating to 1999. For comparison purposes, the dataset was similarly restricted for incarcerated men $(N=183,355)$. Incarceration records were standardized and probabilistically linked to maternal information captured in roughly 7.5 million vital records corresponding to all births registered in California. Linkages were based on a combination of unique (e.g., Social Security numbers) and nonunique (e.g., first name, last name, date of birth) personal maternal identifiers common to both files. An opensource linkage program was used to match records; the linkage algorithm was developed through an iterative process of clerically reviewing record pairs and then retraining the algorithm using machine learning methods. Matches and nonmatches were classified based on score thresholds and a manual review of record pairs falling above, below, and between score boundaries. After linkages were completed, records were stripped of all direct identifiers and reintegrated with fields needed for analysis. Data security practices and research activities fell under protocols approved by the state's committee for the protection of human subjects and a university institutional review board.

\section{Variables}

Variables from prison records were coded categorically to characterize the population of incarcerated women based on demographics, offense type, timing of incarceration episode, and birth events. Offense types were coded categorically, corresponding to most recent offense type: (a) violent (e.g., murder, assault), (b) property (e.g., petty theft, burglary), (c) drug (e.g., manufacturing, possession), or (d) other (e.g., arson, kidnapping). Age at incarceration for the prison episode spanning 2010-2012 was calculated using the entry date and the woman's date of birth. Episode duration was calculated using start and end dates for the incarceration episode falling in the 2010-2012 window ( $<1$ year, $\geq 1$ year).
For women whose incarceration began in the second half of 2012, we had right-censored episode duration data.

Mothers were defined as anyone linked to a California birth record between 1999 and 2012. For mothers who gave birth more than once during this period, we focused on the characteristics documented in the vital record for the first birth. The birth record was used to code mothers by age at the time of birth as a continuous variable and similarly, the youngest child's age at the start of the mother's most recent incarceration episode (between 2010 and 2012). Variables included maternal education (less than a high school degree, high school degree or more), paternity (established, missing), birth payment method (public, private), and number of births between 1999 and 2012 (one, two or more). Race or ethnicity was categorized based on coding that was reflected in administrative records for the three largest populations of incarcerated women (White, Black, and Hispanic) and a fourth category (Other) captured smaller populations as well as missingness.

\section{Analysis}

The total number of incarcerated women in the study population and the number of women entering state prison each year were documented. Descriptive information was calculated concerning offense type. Chi-square tests and $t$-tests examined bivariate group differences between women in prison who were identified as mothers versus nonmothers. Multinomial logistic regression models were specified to compute estimated relative risk ratios (RRRs) with corresponding 95\% confidence intervals (95\% CIs) for each offense type among mothers and nonmothers. Statistical analyses were conducted using Stata-MP (version 15.1).

\section{Results}

Figure 1 displays the number of incarcerated women entering state prison between 2010 and 2012, in addition to the total population of incarcerated women each year. Overall, 16,932 women aged 44 or younger were incarcerated in California state prisons between 2010 and 2012. Consistent with realignment, these data document a notable decline in the size of the cohort entering state prison each year and a corresponding drop in the number of incarcerated women overall. Although not included in the figure, we computed the number of men aged 44 or younger entering prison in the same time period $(N=135,268)$. The number of men entering each year decreased $67.8 \%$ between 2010 and 2012, whereas the number of women decreased $78.5 \%$ (from 6701 in 2010 to 1444 in 2012). In 
Fig. 1 California's incarcerated women population by year (2010-2012). The dark bars identify the number of women entering prison during each year as a new incarceration event. The light bars identify the total number of unique women incarcerated during a calendar year. The trend for both lines shows fewer women entering prison, and fewer total women incarcerated, during each calendar year

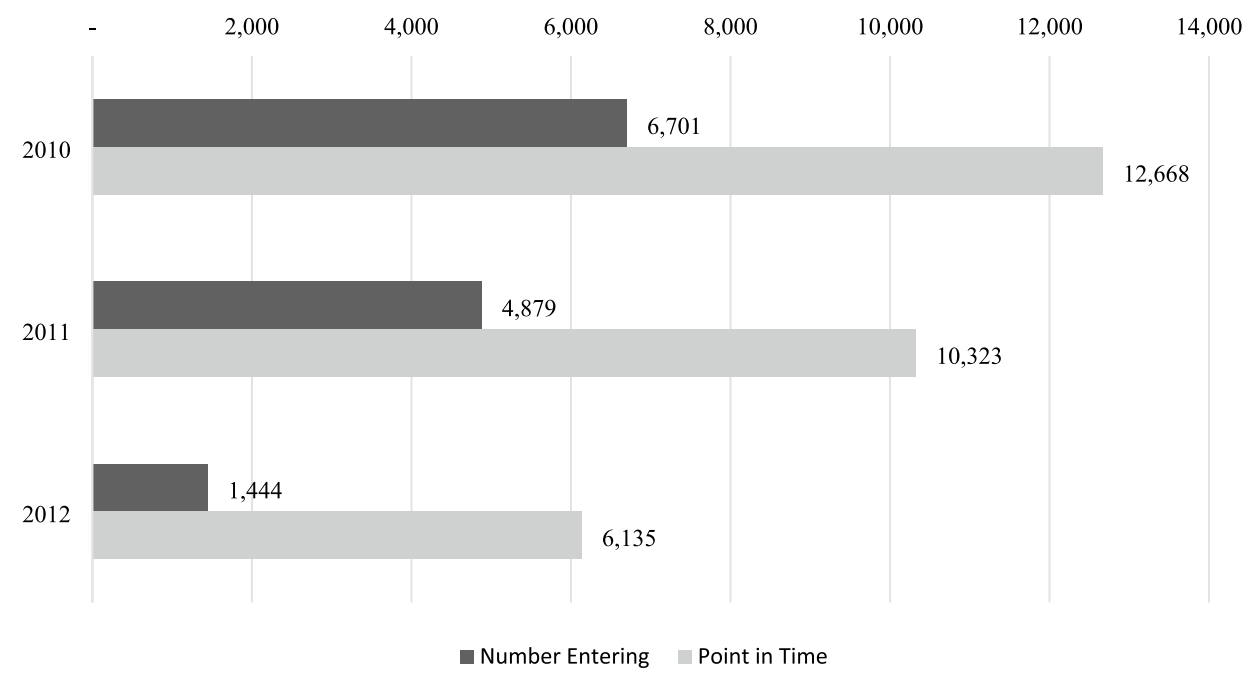

\begin{tabular}{|c|c|c|c|c|c|c|c|}
\hline & \multicolumn{6}{|c|}{ Most recent offenses $(N=16,932)$} & \multirow[b]{3}{*}{$\chi^{2}$ trends } \\
\hline & \multicolumn{2}{|c|}{$2010(n=12,668)$} & \multicolumn{2}{|c|}{$2011(n=10,323)$} & \multicolumn{2}{|c|}{$2012(n=6,135)$} & \\
\hline & $\mathrm{N}$ & $\operatorname{col} \%$ & $\mathrm{~N}$ & $\operatorname{col} \%$ & $\mathrm{~N}$ & $\operatorname{col} \%$ & \\
\hline \multicolumn{8}{|l|}{ Felony type } \\
\hline Violent $(0 / 1)$ & 2201 & 17.4 & 2109 & 20.4 & 1945 & 31.7 & $450.0 * * *$ \\
\hline Property $(0 / 1)$ & 6157 & 48.6 & 4995 & 48.4 & 2664 & 43.4 & $35.9 * * *$ \\
\hline Drug related $(0 / 1)$ & 3489 & 27.5 & 2517 & 24.4 & 1018 & 16.6 & $252.8 * * *$ \\
\hline Other $(0 / 1)$ & 821 & 6.5 & 702 & 6.8 & 508 & 8.3 & 18.1 *** \\
\hline
\end{tabular}

Yearly values represent all women incarcerated during that time, and the total number of women incacerated by year can be observed to have decreased. The aggregate number of unique women incacerated during this period was 16,932. Offenses were coded into categories: (a) violent (e.g., murder, assault), (b) property (e.g., petty theft, burglary), (c) drug (e.g., manufacturing, possession), or (d) other (e.g., arson, kidnapping)

$* p<0.05, * * p<0.01, * * * p<0.001$

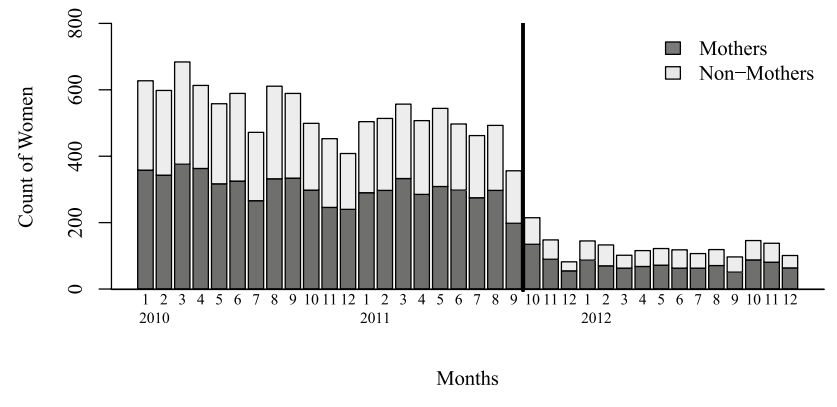

Fig. 2 Number of women entering prison by month (2010-2012). Monthly entrances are shown by maternal status for 2010 through 2012. The vertical line denotes the implementation of realignment on October 1, 2011

2010 , women made up $8.2 \%$ of the state prison population compared to only $5.9 \%$ in 2012 .
Table 1 shows the felony types among incarcerated women by year. The chi-square test for trends showed that all offenses types changed significantly before and after realignment. Notably, the proportion of women incarcerated for violent offenses increased (from $17.4 \%$ to $31.7 \%$ ), although the overall number of women incarcerated for violent offenses decreased slightly. In 2010, a quarter of women $(27.5 \%)$ were incarcerated for property crimes, which decreased to $16.6 \%$ in 2012 .

The birth linkage showed that $54.3 \%(n=9192)$ of women in California's prison population had given birth at least once. Figure 2 depicts the number of women entering over time by month before and after realignment (October 1, 2011) and by mothers and nonmothers. Consistently over time, the majority of incarcerated women were mothers.

As shown in Table 2, incarcerated mothers and nonmothers differed significantly. On average, mothers were older than nonmothers $(p<0.001)$. Incarceration episodes 
Table 2 Incarceration differences between incarcerated mothers and nonmothers

\begin{tabular}{|c|c|c|c|c|}
\hline & \multicolumn{4}{|l|}{ Maternal incarceration } \\
\hline & $\begin{array}{l}\text { All incarcerated women } \\
(N=16,932)\end{array}$ & $\begin{array}{l}\text { Non-mothers } \\
(\mathrm{n}=7741)\end{array}$ & $\begin{array}{l}\text { Mothers } \\
(\mathrm{n}=9191)\end{array}$ & \\
\hline & Mean (sd) & Mean (sd) & Mean (sd) & $T$-test \\
\hline \multicolumn{5}{|l|}{ Incarceration records } \\
\hline Age at incarceration (2010-2012) & $\begin{array}{l}31.0(7.15) \\
\text { col\% }\end{array}$ & $\begin{array}{l}32.3(8.05) \\
\text { col\% }\end{array}$ & $\begin{array}{l}29.9(6.07) \\
\mathrm{col} \%\end{array}$ & $\begin{array}{l}21.7 * * * \\
\chi^{2}\end{array}$ \\
\hline \multicolumn{5}{|l|}{ Episode duration (2010-2012) } \\
\hline $\begin{array}{l}<1 \text { year } \\
\geq 1 \text { year }\end{array}$ & $\begin{array}{l}54.9 \\
45.1\end{array}$ & $\begin{array}{l}49.3 \\
50.7\end{array}$ & $\begin{array}{l}59.7 \\
40.4\end{array}$ & $183.64 * * *$ \\
\hline \multicolumn{5}{|l|}{ Felony type (2010-2012) } \\
\hline Violent $(0 / 1)$ & 20.0 & 21.7 & 18.5 & $28.08 * * *$ \\
\hline Property $(0 / 1)$ & 53.0 & 50.2 & 55.2 & $39.89 * * *$ \\
\hline Drug related $(0 / 1)$ & 30.4 & 30.9 & 30.0 & 1.94 \\
\hline Other $(0 / 1)$ & 7.0 & 7.0 & 6.9 & 0.22 \\
\hline Birth records & & & Mean (sd) & \\
\hline Child age & - & - & $4.8(3.1)$ & \\
\hline Maternal age & - & - & $25.7(5.7)$ & \\
\hline Racial/ethnic category & & & $\operatorname{col} \%$ & \\
\hline White & - & - & 22.2 & \\
\hline Black & - & - & 14.8 & \\
\hline Hispanic & - & - & 42.0 & \\
\hline Other & - & - & 21.0 & \\
\hline \multicolumn{5}{|l|}{ Maternal education } \\
\hline Less than a high school degree & - & - & 50.3 & \\
\hline High school degree or more & - & - & 49.7 & \\
\hline \multicolumn{5}{|l|}{ Paternity } \\
\hline Established & - & - & 64.7 & \\
\hline Missing & - & - & 35.3 & \\
\hline \multicolumn{5}{|l|}{ Birth payment method } \\
\hline Public & - & - & 72.0 & \\
\hline Private & - & - & 28.1 & \\
\hline \multicolumn{5}{|l|}{ Number of births } \\
\hline One birth & - & - & 62.3 & \\
\hline Two or more births & - & - & 37.7 & \\
\hline
\end{tabular}

Not all column will sum to $100 \%$ due to rounding. Felony type variables are dichotomous varables, and each row accounts for all women, representing $100 \%$ of the population. Data on race and ethnicity were not available for women who were not mothers

$* p<0.05, * * p<0.01, * * * p<0.001$ were significantly shorter for mothers compared to nonmothers. Although no differences in drug-related or other offenses were observed based on having given birth, mothers were more likely to have committed a property crime $(55.2 \%$ vs $50.2 \%, p<0.001)$ and less likely to have committed a violent crime $(18.5 \%$ vs $21.7 \%, p<0.001)$. Birth records showed Hispanic mothers made up the largest proportion of births among incarcerated women (42.0\%). About half of mothers had a high school degree (49.7\%), a third of mothers had missing paternity on the 
Fig. 3 Predictive margins showing differences in the likelihood of each felony type for mothers (compared to nonmothers). The reference group for the model was violent offenses and nonmothers. Point estimates identify the risk ratios for mothers compared to nonmothers in each offense type. RRR and $95 \%$ confidence $(95 \% \mathrm{CI})$

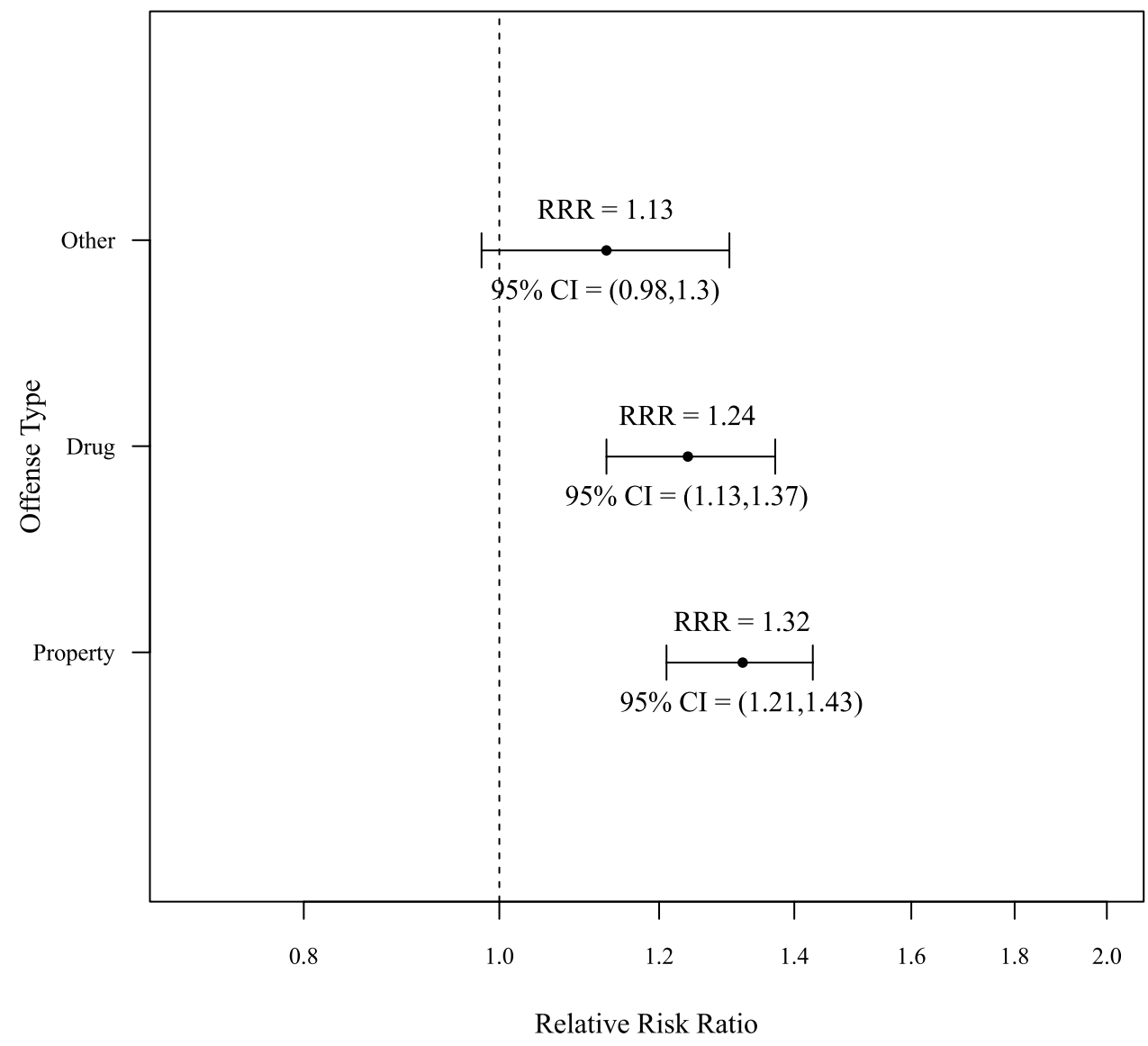

birth record (35.3\%), $72.0 \%$ of mothers gave birth covered with public insurance, and the majority of women $(62.3 \%)$ had one birth during the study period.

Figure 3 presents findings from the age-adjusted multinomial model used to examine the likelihood of offense type by maternal status. An analysis of variance showed that age was significantly related to offense type $(F=106.1, p<0.001)$; however, the introduction of age shifted the estimates only slightly. Findings suggest that mothers were significantly more likely than nonmothers to be incarcerated for property and drug offenses compared to violent offenses (property: $R R=1.32,95 \%$ CI $1.20,1.43$; drug: $R R=1.24,95 \%$ CI 1.12 , 1.36).

\section{Discussion}

Few studies have used linked administrative data at a population-level to identify the number of incarcerated women with children (Brazzell, 2008; Dowell et al., 2017; Gifford et al., 2021). Researchers have highlighted the importance of using administrative data to better measure the effects of the incarceration experience for parents and children (Sabol, 2016). Importantly, the current study is the first to leverage linked administrative data to examine maternal incarceration during a period in which state penalties for low-level offenders changed. Consistent with other studies and expectations, prison records document that California's efforts to "realign" correctional responsibilities for many offenders from state prisons to county jails had a profound effect on the size and demographics of the prison population. This examination is especially timely given the pressure to reduce crowding within prisons in response to COVID outbreaks, alongside growing pressure from advocates to better address mass incarceration (Kang-Brown et al., 2021). Beyond immediate pressures to reduce prison populations due to health and safety concerns, the COVID-19 pandemic is also placing a financial strain on governments, which may be pressed to reduce incarcerated populations to address budget deficits. At least five key findings emerged that have implications for policy, practice, and research.

First, the current study showed realignment has disproportionately affected women; while the number of men entering state prison decreased $67.8 \%$, the number of women entering state prison decreased $78.5 \%$ (from 6701 in 2010 to 1444 in 2012). The decrease in women entering state prison was notable, even accounting for concurrent increases in county jail populations statewide. State reports show 9245 women were in county jails statewide in 2012 , and the number increased to 9891 in 2014 (a 7.0\% increase; BSCC, 
2019). Taken together, these data indicate that fewer women are incarcerated in California following realignment.

Second, not only did the population of women in prison shrink, but the reasons for incarceration changed. Women incarcerated for drug-related offenses in 2010 amounted to $27.5 \%$ of the population, and that number shrank to $16.6 \%$ in 2012. The trend for violent offenses was almost reversed among women, with $17.4 \%$ of entries due to violent offenses in 2010 and $31.7 \%$ of incarcerations due to violent offenses in 2012. The number of women incarcerated for violent offenses remained slightly smaller but largely unchanged before and after realignment. The number of individuals incarcerated in state prison for violent crimes remained the same after realignment. The policy only moved management of low-level offenders to county systems, and offenders for violent crimes continue to enter state prison.

Third, the majority of women incarcerated in prison were mothers, a finding that is consistent before and after realignment. Children with justice-involved mothers are more likely to experience an arrest, conviction, and incarceration during adulthood (Armstrong et al., 2018; Foster, 2012; Foster \& Hagan, 2013). The likelihood of next-generation effects highlights the importance of better understanding maternal incarceration. Fourth, offense type and episode length differed between mothers and nonmothers. Compared to incarcerated women who were nonmothers, mothers were significantly more likely to be incarcerated for property and drug offenses and less likely to be incarcerated for violent offenses. Episode length tended to be shorter for mothers, which may be related to the nature of the offense that led to incarceration. Given that fewer women are being incarcerated in prison for drug offenses after realignment and mothers are more likey to commit drug offenses, improved substance abuse services in county jails and the community could be particularly helpful in addressing the criminogenic needs of justice-involved mothers. In addition to improving substance abuse services, preventative measures can be taken through policy change to decrease the severity of charges for non-violent crimes or to provide alternatives, as well as fund improvements in the efficacy of linkage between individuals and community resources upon release from state prison or county jail.

Fifth, the data suggest that mothers incarcerated in state prison have different birth characteristics than nonincarcerated mothers in California. In comparison to demographics documented using California's birth records (PutnamHornstein \& Needell, 2011; Schneiderman et al., 2021), incarcerated mothers were more likely to be Black $(15 \%$ vs. $5 \%$ ), less likely to have a high school degree (50\% vs. $73 \%$ ), less likely to have paternity established on the birth record (65\% vs. 93\%), and more likely to have public health insurance (an indicator of lower income; $72 \%$ vs. $49 \% \%$ ) when compared to all mothers. These findings align with research showing Black women are overrepresented among women in prison (Gifford et al., 2021) and suggests nextgeneration consequences of pervasive racial differences in criminal justice involvement and incarceration (Wakefield \& Wildeman, 2011). Future research should examine the effect of increased reliance on county justice systems and alternatives to incarceration on women and mothers with justice system involvement and children with incarcerated mothers, particularly among children born to Black mothers. Further, it is unknown if reductions in female incarceration have affected the need for or duration of out-of-home foster care placements in California, a population in which Black children are overrepresented (Dettlaff \& Boyd, 2020). However, prior research has established a relationship between maternal incarceration and both child protective services involvement and the termination of parental rights (Dworsky et al., 2011; Gifford et al., 2021).

\section{Limitations}

Although this study leveraged linked, population-level data, the generalizability of findings should be considered in light of available data. California's realignment provided a unique opportunity to examine policy changes that decreased the number of incarcerated individuals and the resulting effect on mothers. However, changes in local and state jurisdiction for low-level offenses may yield different results in other regions. Some mothers may be inaccurately classified as nonmothers because the observation window was limited to California births in or after 1999. Data were restricted to only one offense type per incarceration episode and did not examine all offense types for which women were incarcerated.

\section{Conclusion}

The current analysis documented maternal incarceration and underscores the effect of increased reliance on local (as opposed to state) criminal justice systems in response to lower-level offenses on reducing the levels of prison incarceration for women and mothers. States considering similar measures to reduce reliance on incarceration or to shift responsibility of low-level offenders to local systems should consider the effect of realignment on women and mothers as they redirect how similar policy changes may affect their jurisdiction. The majority of women incarcerated in state prisons were mothers across all years, and the study documented differences between incarcerated mothers and nonmothers. These data have implications for California's child population given next-generation risks, particularly for lowincome and Black communities disproportionately affected by incarceration. This work has national implications given 
the stress the COVID-19 pandemic places on government budgets, which may require a reduced reliance on incarceration for nonserious offenses.

Acknowledgements The Children's Data Network receives essential infrastructure funding from First 5 LA (Grant No. 08576), the Con$\operatorname{rad}$ N. Hilton Foundation (Grant No. 17137), and the Heising-Simons Foundation (Grant No. 0809) that made this project possible. This project was also possible thanks to a collaboration with our colleagues at the California Department of Corrections and Rehabilitation (CDCR). The authors would like to thank CDCR for investments in generating new knowledge through the linkage and analysis of administrative data. Although the findings reported and conclusions drawn from these data are solely those of the authors and should not be considered to reflect those of any agency of the County or California government, this analysis would not be possible without the partnership of the Departments, reflecting their ongoing commitment to data-driven program and policy development.

\section{References}

Armstrong, G. S., Muftic, L. R., \& Bouffard, L. A. (2018). Factors influencing law enforcement responses to child to parent violence. Journal of Interpersonal Violence, 36(9-10), NP4979-NP4997. https://doi.org/10.1177/0886260518794510

Bird, M., Grattet, R., \& Nguyen, V. (2017). Realignment and recidivism in California. Public policy institute of California. Retrieved October 13, 2021, from https://www.ppic.org/wp-content/uploa ds/r_1217mbr.pdf

Bloom, B., Owen, B., Covington, S., \& Raeder, M. (2003). Research, practice, and guiding principles for women offenders. National institute of corrections. Retrieved October 13, 2021, from https:// s3.amazonaws.com/static.nicic.gov/Library/018017.pdf

Brazzell, D. (2008). Using local data to explore the experiences and needs of children of incarcerated parents: Research report. Urban institute justice policy center. Retrieved December 21, 2020, from https://www.aecf.org/resources/using-local-data-to-explore-theexperiences-and-needs-of-children-of-incarc/\#findings-and-stats

Bronson, J., \& Carson, E. A. (2019). Prisoners in 2017. U.S. Department of justice office of justice programs. Retrieved December 21, 2020, from https://bjs.ojp.gov/content/pub/pdf/p17.pdf

Bronson, J., \& Sufrin, C. (2019). Pregnant women in prison and jail don't count: Data gaps on maternal health and incarceration. Public Health Reports, 134(1_suppl), 57S-62S. https://doi.org/ $10.1177 / 0033354918812088$

Brown v. Plata, 563 US 493, No. 09-1233 (Supreme Court of the United States 2011). Retrieved February 6, 2020, from https:// supreme.justia.com/cases/federal/us/563/493/

BSCC. (2019). Jail Population Trends Through Q3 2019. California Board of State and Community Corrections. Retrieved October 13, 2021, from http://www.bscc.ca.gov/wp-content/uploads/JailPop-Trends-Through-Q3-2019.pdf

Carson, E. A. (2020a). Prisoners in 2018. U.S. Department of Justice Office of Justice Programs. Retrieved February 6, 2020, from https://bjs.ojp.gov/content/pub/pdf/p18.pdf

Carson, E. A. (2020b). Prisoners in 2019. U.S. Department of Justice Office of Justice Programs. Retrieved February 6, 2020, from https://bjs.ojp.gov/content/pub/pdf/p19.pdf

Dettlaff, A. J., \& Boyd, R. (2020). Racial disproportionality and disparities in the child welfare system: Why do they exist, and what can be done to address them? The ANNALS of the American Academy of Political and Social Science, 692(1), 253-274. https://doi. org/10.1177/0002716220980329
Dowell, C. M., Preen, D. B., \& Segal, L. (2017). Quantifying maternal incarceration: A whole-population linked data study of Western Australian children born 1985-2011. Australian and New Zealand Journal of Public Health, 41(2), 151-157. https://doi.org/10.1111/ 1753-6405.12613

Dworsky, A., Harden, A., \& Goerge, R. (2011). The relationship between maternal incarceration and foster care placement. The Open Family Studies Journal, 4(1), 117-121. https://doi.org/10. 2174/1874922401104010117

Foster, H. (2012). The strains of maternal imprisonment: Importation and deprivation stressors for women and children. Journal of Criminal Justice, 40(3), 221-229. https://doi.org/10.1016/j. jcrimjus.2012.01.005

Foster, H., \& Hagan, J. (2013). Maternal and paternal imprisonment in the stress process. Social Science Research, 42(3), 650-669. https://doi.org/10.1016/j.ssresearch.2013.01.008

Geller, A., Jaeger, K., \& Pace, G. T. (2016). Surveys, records, and the study of incarceration in families. The ANNALS of the American Academy of Political and Social Science, 665(1), 22-43. https:// doi.org/10.1177/0002716216633449

Gifford, E. J., Golonka, M., \& Evans, K. E. (2021). Maternal imprisonment and the timing of children's foster care involvement. In J. Poehlmann-Tynan \& D. Dallaire (Eds.), Children with incarcerated mothers: Separation, loss, and reunification (pp. 75-90). Springer International Publishing.

Glaze, L. E., \& Maruschak, L. M. (2008). Parents in Prison and Their Minor Children. U.S. Department of justice office of justice programs. Retrieved October 13, 2021, from https://bjs.ojp. gov/content/pub/pdf/pptmc.pdf

Grattet, R., Tafoya, S., Bird, M., \& Nguyen, V. (2016). California's county jails in the era of reform. Public policy institute of California. Retrieved October 5, 2020, from https://www.ppic.org/ content/pubs/report/R_916RGR.pdf

Harner, H. M., \& Riley, S. (2013). The impact of incarceration on women's mental health: Responses from women in a maximumsecurity prison. Qualitative Health Research, 23(1), 26-42. https://doi.org/10.1177/1049732312461452

Kang-Brown, J., Montagnet, C., \& Heiss, J. (2021). People in Jail and Prison in 2020. Vera Institute of Justice.

Kruttschnitt, C. (2010). The paradox of women's imprisonment. Daedalus, 139(3), 32-42. https://doi.org/10.1162/DAED_a_00021

Lee, R. D., Fang, X., \& Luo, F. (2016). Parental incarceration and social exclusion: Long-term implications for the health and wellbeing of vulnerable children in the United States. In J. A. Bishop \& J. G. Rodríguez (Eds.), Inequality after the 20th century: Papers from the sixth ECINEQ meeting (Vol. 24, pp. 215-234). Emerald Group Publishing Limited.

Lofstrom, M., \& Raphael, S. (2015). Realignment, Incarceration, and Crime Trends in California. Public Policy Institute of California. Retrieved October 17, 2020, from https://www.ppic.org/content/ pubs/report/R_515MLR.pdf

Mignon, S. (2016). Health issues of incarcerated women in the United States. Ciência \& Saúde Coletiva, 21(7), 2051-2060. https://doi. org/10.1590/1413-81232015217.05302016

Putnam-Hornstein, E., \& Needell, B. (2011). Predictors of child protective service contact between birth and age five: An examination of California's 2002 birth cohort. Children and Youth Services Review, 33(8), 1337-1344. https://doi.org/10.1016/j.childyouth. 2011.07.010

Sabol, W. J., Minton, T. D., \& Harrison, P. M. (2007). Prison and Jail Inmates at Midyear 2006. U.S. Department of Justice Bureau of Justice Statistics. Retrieved September 27, 2021, from https://bjs. ojp.gov/content/pub/pdf/pjim06.pdf

Sabol, W. J. (2016). Commentary: Could linked data help us to better understand the macrolevel consequences of mass imprisonment? The ANNALS of the American Academy of Political and Social 
Science, 665(1), 213-221. https://doi.org/10.1177/0002716216 633446

Schneiderman, J. U., Prindle, J., \& Putnam-Hornstein, E. (2021). Infant deaths from medical causes after a maltreatment report. Pediatrics, 148(3), e2020048389. https://doi.org/10.1542/peds. 2020-048389

Tripodi, S. J., \& Pettus-Davis, C. (2013). Histories of childhood victimization and subsequent mental health problems, substance use, and sexual victimization for a sample of incarcerated women in the US. International Journal of Law and Psychiatry, 36(1), 30-40. https://doi.org/10.1016/j.ijlp.2012.11.005

Wakefield, S., \& Wildeman, C. (2011). Mass imprisonment and racial disparities in childhood behavioral problems. Criminology \& Public Policy, 10(3), 793-817. https://doi.org/10.1111/j.1745-9133. 2011.00740.x

Walmsley, R. (2017). World female imprisonment list: Women and girls in penal institutions, including pre-trial detainees/remand prisoners. World Prison Brief. Retrieved October 26, 2020, from https://www.prisonstudies.org/sites/default/files/resources/downl oads/world_female_prison_4th_edn_v4_web.pdf

Wildeman, C., Goldman, A. W., \& Turney, K. (2018). Parental incarceration and child health in the United States. Epidemiologic Reviews, 40(1), 146-156. https://doi.org/10.1093/epirev/mxx013

Zhao, Q., Cepeda, A., Chou, C.-P., \& Valdez, A. (2021). Incarceration trajectories of women who are mothers: A nationally representative study of state and federal prisoners. Crime \& Delinquency, 67(10), 1513-1535. https://doi.org/10.1177/0011128720974315

Zhen, Z., \& Milton, T. D. (2021). Jail Inmates in 2019. U.S. Department of Justice Office of Justice Programs. Retrieved February 6, 2020, from https://bjs.ojp.gov/content/pub/pdf/ji19.pdf

Publisher's Note Springer Nature remains neutral with regard to jurisdictional claims in published maps and institutional affiliations. 